\title{
STRATEGI MENINGKATKAN DAYA SAING BISNIS PADA USAHA JASA WARNET FILISTIN DI ATAMBUA KABUPATEN BELU
}

\author{
Felisisima Afoan ${ }^{1}$ \\ Felisisima.afoan27@gmail.com \\ Imaculata Ut Halek ${ }^{2}$ \\ Prodi. Manajemen Fakultas Ekonomi dan Bisnis UNIMOR
}

\begin{abstract}
ABSTRAK
Penyedia jasa internet yang berada di Kabupaten Belu, salah satunya merupakan Warnet Filistin. Oleh karena banyaknya usaha lain yang sejenis hadir diantara Warnet Filistin, mengakibatkan berkurangnya pengunjung yang datang. Warnet Filistin perlu melakukan pengembangan usaha melalui strategi sebagai pijakan dan petunjuk dalam rangka mencapai tujuan jangka panjang. Tujuan penelitian ini untuk menemukan faktor-faktor lingkungan internal dan eksternal serta dapat menemukan strategi apa yang dapat digunakan pada jasa Warnet Filistin sehingga dapat bertahan dan bersaing dalam usaha yang sejenis. Penelitian yang dilakukan bersifat operasional dan teknik pengumpulan datanya dilakukan dengan cara observasi, kuesioner dan wawancara. Analisis yang digunakan adalah metode analisis kuantitatif dengan alat analisis SWOT. Hasil analisis data melalui matrik IFAS(Internal Factor Analysis Summary) dan matrik EFAS (Eksternal Factor Analysis Summary) yang diperoleh, Warnet Filistin memiliki bobot yang baik dimana dalam lingkungan internal yang berada dalam posisi Strengths yaitu dengan selisih (1.64) dan lingkungan eksternal yang berada pada posisi Opportunity dengan skor (1.12), sehingga dapat disimpulkan bahwa posisi diagram SWOT pada Warnet Filistin berada pada posisi kuadran I (satu) yaitu strategi $S O$ yang menunjukan bisnis usaha ini memiliki peluang dan banyaknya kekuatan yang mendorong dan dimanfaatkannya peluang tersebut.
\end{abstract}

Kata Kunci: Daya Saing, Usaha Jasa, Analisis SWOT

\section{PENDAHULUAN}

Dalam era globalisasi, semakin banyak teknologi yang dapat mempermudah manusia dalam melakukan berbagai aktivitas kehidupan. Dengan demikian tidak diragukan lagi bahwa teknologi mempunyai peran penting dalam kehidupan manusia di berbagai sektor yaitu di bidang transportasi, komunikasi, kesehatan, pendidikan dan bidang lainnya.

Saat ini dunia telah mengenal suatu teknologi yang dinamakan internet. Melalui internet semua orang dapat berkomunikasi dengan orang lain yang berada di berbagai belahan dunia. Melalui dunia ini pula mereka dapat memperoleh dan menyampaikan berbagai informasi yang dibutuhkan kapan dan di mana saja. Dengan adanya jaringan di warnet (warung internet) dapat diakses 24 jam sehari; dalam 
hitungan detik kita dapat memperoleh informasi apa saja yang kita butuhkan dengan mengakses internet.

Internet tidak hanya dapat digunakan dalam mencari informasi saja tetapi media internet juga dapat digunakan oleh berbagai kalangan dalam melakukan usaha bisnisnya misalnya online store, services/layanan dan lain-lain. Warung internet merupakan salah satu peluang bisnis di sektor jasa dengan pasar potensial yang terus berkembang. Kondisi seperti ini dimanfaatkan oleh beberapa penyedia jasa warnet di manapun berada termasuk di Atambua.

Warnet Filistin didirikan pada tanggal 29 september 2012 oleh bapak Dominikus Nahak, yang terletak di Jalan Mohamad Yamin, Kelurahan Rinbesi, Kecamatan Atambua Selatan, Kabupaten Belu. Sejak awal didirikan warnet ini, tidak terdapat warnet di lingkungan sekitarnya jadi belum ada persaingan. Dalam perjalanan bisnis warnet Filistin, ada beberapa warnet lain yang bermunculan sehingga menyebabkan persaingan bisnis yang semakin ketat, bahkan warnet filistin di apit oleh 2 buah usaha warnet lain dalam radius $200 \mathrm{M}^{2}$ yang berdampak terhadap berkurangnya pelanggan. Hal inilah yang membuat warnet Filistin membutuhkan strategi yang lebih inovatif dan efektif agar dapat mengatasi persaingan tersebut.

Berikut jumlah pelanggan selama dua tahun terakhir yaitu dari tahun 20152016 dengan tarif $\mathrm{Rp} 6.000$,- /jam sebagai berikut:

Tabel 1.1

Jumlah Pelanggan Warnet Filistin Atambua

Tahun 2016-2017

\begin{tabular}{|c|c|c|c|c|}
\hline \multirow[b]{2}{*}{ No } & \multicolumn{2}{|c|}{ Tahun 2016} & \multicolumn{2}{|c|}{ Tahun 2017} \\
\hline & Bulan & $\begin{array}{c}\text { Jumlah } \\
\text { Pelanggan }\end{array}$ & Bulan & $\begin{array}{c}\text { Jumlah } \\
\text { Pelanggan }\end{array}$ \\
\hline 1 & Januari & 1.410 & Januari & 1.350 \\
\hline 2 & Februari & 1.310 & Februari & 872 \\
\hline 3 & Maret & 1.553 & Maret & 995 \\
\hline 4 & April & 1.450 & April & 901 \\
\hline 5 & Mei & 1.447 & Mei & 763 \\
\hline 6 & Juni & 1.529 & Juni & 572 \\
\hline 7 & Juli & 1.552 & Juli & 460 \\
\hline 8 & Agustus & 1.438 & Agustus & 673 \\
\hline
\end{tabular}




\begin{tabular}{|c|l|c|l|c|}
9 & September & 1.502 & September & 664 \\
\hline 10 & Oktober & 1.428 & Oktober & 579 \\
\hline 11 & November & 1.378 & November & 596 \\
\hline 12 & Desember & 1.236 & Desember & 375 \\
\hline & Jumlah & $\mathbf{1 7 . 2 3 3}$ & Jumlah & $\mathbf{8 . 8 0 0}$ \\
\hline
\end{tabular}

Sumber: Warnet Filistin Atambua 2018

Dari data di atas dapat diketahui bahwa jumlah pelanggan warnet Filistin sejak tahun 2015-2016 setiap bulannya cendrung menurun yaitu dengan adanya kompetiter atau pesaing. Kemungkinan dengan adanya usaha yang sejenis tersebut yang membuat berkurangnya pelanggan di warnet Filistin. Kekuatan merupakan sumber daya dan keterampilan ataupun keunggulan lain yang dimiliki suatu perusahaan yang merupakan pijakan strategi atau landasan yang di atasnya dapat dibangun langkah-langkah kompetisi yang menguntungkan. Untuk itu kekuatan pada warnet Filistin yaitu tempat yang strategis, pengelolanya yang kompeten, mempunyai bisnis lain selain warnet, sudah memiliki izin usaha.

Kelemahan merupakan keterbatasan atau kekurangan dalam hal sumber daya alam maupun sumber daya manusia. Kelemahan pada usaha jasa warnet Filistin yaitu ruangan yang kurang nyaman, jumlah ruangan yang terbatas, kurangnya promosi, gedungnya masih disewa.

Peluang merupakan lingkungan luar perusahaan, sehingga perusahaan tidak dapat menghilangkan atau menciptakan sebuah peluang. Perusahaan hanya dapat mencari informasi mengenai peluang-peluang yang ada di pasar. Peluang bisnis pada usaha jasa warnet Filistin yaitu meningkatnya pemakai jasa warnet, adanya kemudahan oleh PT. Telkom Tbk, dan kemajuan teknologi informasi, transportasi dan komunikasi.

Ancaman merupakan tantangan akibat kecendrungan yang tidak menguntungkan atau perkembangan yang akan mengurangi penjualan atau laba bila tidak dilakukan gerakan defensive. Berikut ancaman pada usaha jasa warnet yaitu banyak bermunculan usaha yang sejenis, kebanyakan orang sudah memiliki computer sendiri, dan tersedianya wifi gratis di tempat-tempat pelayanan umum. 
Atas kondisi tersebut, pengelola usaha jasa warnet Filistin harus mengetahui sampai sejauh mana situasi persaingan usaha serta analisis lingkungan yang mempengaruhi usahanya sehingga pengelola dapat mengambil strategi yang tepat untuk memajukan bisnisnya. Selanjutnya usaha jasa warnet Filistin dapat mengevaluasi kembali mengenai strategi yang diterapkan selama ini apakah sudah sesuai dengan kondisi lingkungan internal dan eksternal yang meliputi kekuatan, kelemahan, peluang dan ancaman kemudian dapat menentukan strategi yang tepat sesuai dengan kondisi lingkungan usaha sehingga dalam mengaplikasikannya dapat berjalan dengan efektif dan efisien guna meningkatkan volume pelanggan warnet Filistin serta dapat meningkatkan daya saingnya. Dari latar belakang diatas, penulis tertarik untuk mengetahui: faktor-fak lingkungan internal yang merupakan kekuatan (strengths) dan kelemahan (weaknesess) dan lingkungan eksternal yang merupakan peluang (opportunities) dan ancaman (threaths) suatu usaha, dan menemukan strategi apa yang dapat digunakan pada usaha jasa warnet Filistin.

\section{METODE}

Penelitian yang dilakukan bersifat operasional dan teknik pengumpulan datanya dilakukan dengan cara observasi, kuesioner dan wawancara. Analisis yang digunakan adalah metode analisis kuantitatif dengan alat analisis SWOT yaitu Internal Factor Analysis Summary (IFAS) dan Eksternal Factor Analysis Summary (EFAS) dimana analisis yang memaksimalkan Strengths dan Opportunities, yang bersamaan juga dapat meminimalkan Weakneses dan Threats. Penelitian ini dilaksanakan pada Usaha Jasa Warnet Filistin di Atambua Kabupaten Belu.

\section{PEMBAHASAN}

Penulis menggunakan pendekatan teori SWOT yaitu analisis Strengths, Weaknesses, opportunities, dan Threats. Pada bagian ini analisis SWOT digunakan untuk menganalisis faktor-faktor strategis internal dalam kerangka Stengths dan 
Weaknesses serta faktor-faktor strategis eksternal dalam kerangka Opportunity dan Threat. Serta untuk menentukan alternatif strategi dan penentuan pilihan strategi pengembangan usaha bisnis jasa warnet Filistin.

a. Matrik Faktor Strategi Internal (Internal Factor Analysis Summary/IFAS)

Setelah melakukan identifikasi terhadap faktor internal perusahaan maka dibuat matriks IFAS yang berisi kekuatan (Strengths) dan kelemahan (weaknesses). Penetapan bobot dan rating dilakukan dengan bersama-sama dengan pihak warnet Filistin (Manager, karyawan dan konsumen).

Penilaian Responden terhadap Internal Factor Analysis Summary (IFAS) pada jasa warnet Filistin dapat dilihat pada tabel 2 berikut:

Tabel 3.1

Matrik Internal Factor Analysis Summary (IFAS) Warnet Filistin Atambua

\begin{tabular}{|c|c|c|c|}
\hline Faktor-Faktor Strategis & \multirow{2}{*}{ Bobot } & \multirow{2}{*}{ Rating } & \multirow{2}{*}{ Skor } \\
\hline Internal & & & \\
\hline \multicolumn{4}{|l|}{ Strengths (S): } \\
\hline Tempat Usaha yang Strategis & 0.12 & 4.0 & 0.48 \\
\hline Memiliki Izin Usaha & O. 11 & 3.7 & 0.41 \\
\hline Manajer Yang Kompeten & 0.13 & 3.3 & 0.43 \\
\hline $\begin{array}{l}\text { Karyawan yang mengerti ten- } \\
\text { tang keutamaan konsumen }\end{array}$ & 0.12 & 3.3 & 0.40 \\
\hline Pengaksesannya yang cepat & O. 13 & 4.0 & 0.52 \\
\hline Sub Total & 0.61 & & 2.24 \\
\hline \multicolumn{4}{|l|}{ Weaknesses $(K)$} \\
\hline Kurangnya promosi & O. 11 & 2.0 & 0.22 \\
\hline $\begin{array}{l}\text { Karyawan yang sulit diper- } \\
\text { caya }\end{array}$ & 0.09 & 1.0 & 0.09 \\
\hline Ruangan kurang nyaman & 0.09 & 1.3 & 0.12 \\
\hline Pengelola karena keterbatasan & \multirow[b]{2}{*}{ O. 10} & \multirow[b]{2}{*}{1.7} & \multirow[b]{2}{*}{ O. 17} \\
\hline $\begin{array}{l}\text { waktu sehingga tidak sesering } \\
\text { mungkin mengontrol warnetnya. }\end{array}$ & & & \\
\hline Sub Total & $\mathbf{0 . 3 9}$ & & 0.60 \\
\hline Total & $\mathbf{1 . 0 0}$ & & 2.84 \\
\hline
\end{tabular}

Sumber: Hasil penelitian yang diolah penulis, 2017

Berdasarkan penilaian responden terhadap faktor kunci internal (Internal Factor Analysis Summary/ IFAS) pada jasa Warnet Filistin, dari hasil analisis tabel 2 diatas terlihat bahwa pengaksesannya yang cepat merupakan kekuatan (strengths) utama yang dimiliki usaha jasa Warnet Filistin. Pengaksesannya yang cepat dengan 
skor 0.52 merupakan faktor yang menentukan dalam kelangsungan hidup jasa warnet Filistin, sehingga dengan pengaksesannya yang cepat ini dapat mempermudah konsumen dalam mengakses suatu informasi yang dibutuhkannya.

Tempat usaha yang strategis merupakan faktor kekuatan (Strengths) kedua yang menentukan dalam kegiatan suatu bisnis dengan skor 0.48 , merupakan kekuatan yang harus dipertahankan baik untuk kegiatan operasional dan pemasaran, sehingga dapat memberikan situasi yang kondusif bagi pihak karyawan maupun konsumen. Memiliki izin usaha merupakan kekuatan yang menentukan dalam kelangsungan hidup suatu usaha atau bisnis. Manager yang kompeten merupakan kekuatan yang keempat dengan skor 0.43 , dimana manager dapat mengoperasi dan memperbaiki komputernya sendiri bila ada kerusakan sehingga tidak memerlukan lagi tenaga teknis. Dengan memiliki izin usaha para karyawan dapat memberikan segenap kemampuannya untuk kemajuan usaha tersebut. Memiliki izin usaha menempati pada posisi ketiga dengan skor 0.41. Karyawan yang mengerti tentang keutamaan konsumen merupakan kekuatan yang kelima dengan skor 0.40 , karena dengan karyawan yang mengerti tentang keutamaan konsumen dapat mencapai tujuan perusahaan.

Kelemahan (weaknesses) utama pada jasa warnet Filistin adalah kurangnya promosi dengan skor 0.22 , kelemahan ini terjadi karena pengelola keterbatasan waktu sehingga tidak sesering mungkin untuk mengontrol usahanya dengan skor 0.17. faktor lain yang menjadi kelemahan pada jasa warnet Filistin adalah ruangan kurang nyaman dengan skor 0.12 , dan karyawan yang sulit dipercaya dengan skor 0.09. sehingga dapat diperoleh faktor Strength mempunyai total nilai skor 2.24 sedangkan weakness mempunyai total nilai skor 0.60 .

b. Matriks Faktor Strategi Eksternal (Eksternal Factor Analysis Summary/EFAS)

Matriks EFAS berisi peluang (Opportunity) dan ancaman (Threat) yang dihadapi oleh perusahaan. Pemberian bobot pada matriks EFAS sama seperti pemberian bobot pada matriks IFAS. 
Penilaian Responden terhadap Eksternal Factor Analysis Summary (EFAS) pada jasa warnet Filistin.

Tabel 3.2

Matrik Eksternal Factor Analysis Summary (EFAS) Warnet Filistin Atambua

\begin{tabular}{|c|c|c|c|}
\hline Faktor-Faktor Strategis & \multirow{2}{*}{ Bobot } & \multirow{2}{*}{ Rating } & \multirow{2}{*}{ Skor } \\
\hline Eksternal & & & \\
\hline \multicolumn{4}{|l|}{ Opportunity (O): } \\
\hline Kemudahan yang diberikan oleh PT. Telkom Tbk & 0.13 & 3 & 0.39 \\
\hline Meningkatnya Pemakai jasa warnet & 0.15 & 3.7 & 0.56 \\
\hline $\begin{array}{l}\text { Banyaknya Bank yang menawarkan kredit dengan } \\
\text { suku bunga bersaing }\end{array}$ & 0.13 & 3 & 0.39 \\
\hline Keadaan jumlah penduduk sekitar & 0.12 & 3.3 & 0.40 \\
\hline Sub Total & 0.53 & & 1.74 \\
\hline \multicolumn{4}{|l|}{ Threats (T): } \\
\hline Muncul usaha yang sejenis & 0.16 & 1 & 0.16 \\
\hline Meningkatnya gaya hidup & 0.13 & 1.7 & 0.22 \\
\hline $\begin{array}{l}\text { Tersedianya jaringan wifi di tempat-rempat } \\
\text { pembelanjaan }\end{array}$ & 0.12 & 1 & 0.12 \\
\hline Persepsi masyarakat terhadap harga & 0.06 & 2 & 0.12 \\
\hline Sub Total & 0.47 & & 0.62 \\
\hline Total & 1 & & 2.36 \\
\hline
\end{tabular}

Sumber: Hasil penelitian yang diolah Penulis, 2017

Berdasarkan penilaian responden terhadap faktor kunci eksternal (Eksternal Factor Analysis Summary/ EFAS) pada jasa warnet Filistin dari analisis tabel 3 terlihat bahwa meningkatnya pemakai jasa warnet merupakan peluang (opportunity) utama dengan skor 0.56, keadaan jumlah penduduk sekitar dengan skor 0.40 merupakan peluang kedua, banyaknya bank yang menawarkan kredit dengan suku bunga bersaing dengan skor 0.39 serta kemudahan yang diberikan PT. Telkom Tbk, dengan skor 0.39 merupakan peluang yang paling mungkin dimanfaatkan oleh jasa warnet Filistin untuk dapat brsaing dengan bisnis lain yang sejenis.

Faktor yang menjadi Threat (ancaman) bagi jasa warnet Filistin sebagian besar berasal dari konsumen dan pesaing. Dimana ancaman utama yang dihadapinya adalah meningkatnya gaya hidup dengan skor 0.22 , banyak bermunculan usaha yang sejenis 
dengan skor 0.16. Selain itu tersedianya jaringan wifi di tempat-tempat pembelanjaan dengan skor 0.12 serta persepsi masyarakat terhadap harga dengan skor 0.12 . Sehingga untuk faktor-faktor Opportunity nilai skornya 1.74 dan faktor Threath 0.62 . Selanjutnya nilai total skor dari masing-masing faktor dapat dirinci sebagai berikut:

-Faktor Kekuatan (Strengths) $\quad: 2.24$

-Faktor Kelemahan (Weaknesses) $\quad: 0.60$

-Faktor Peluang (Opportunities) $\quad: 1.74$

-Faktor Ancaman (Threats) $\quad: 0.62$

Dari hasil penelitian di atas dapat diketahui nilai kekuatan (strengths) dengan skor (2.24) diatas nilai kelemahan (Weaknesses) dengan skor (0.60), sehingga selisih (+) 1.64 dan nilai peluang (opportunity) dengan skor (1.74) dibawah nilai ancaman (threat) dengan skor (0.62) sehingga selisihnya $(+)$ 1.12. Dari hasil identifikasi faktor-faktor tersebut maka dapat digambarkan dalam diagram SWOT

\section{Diagram SWOT Warnet Filistin}

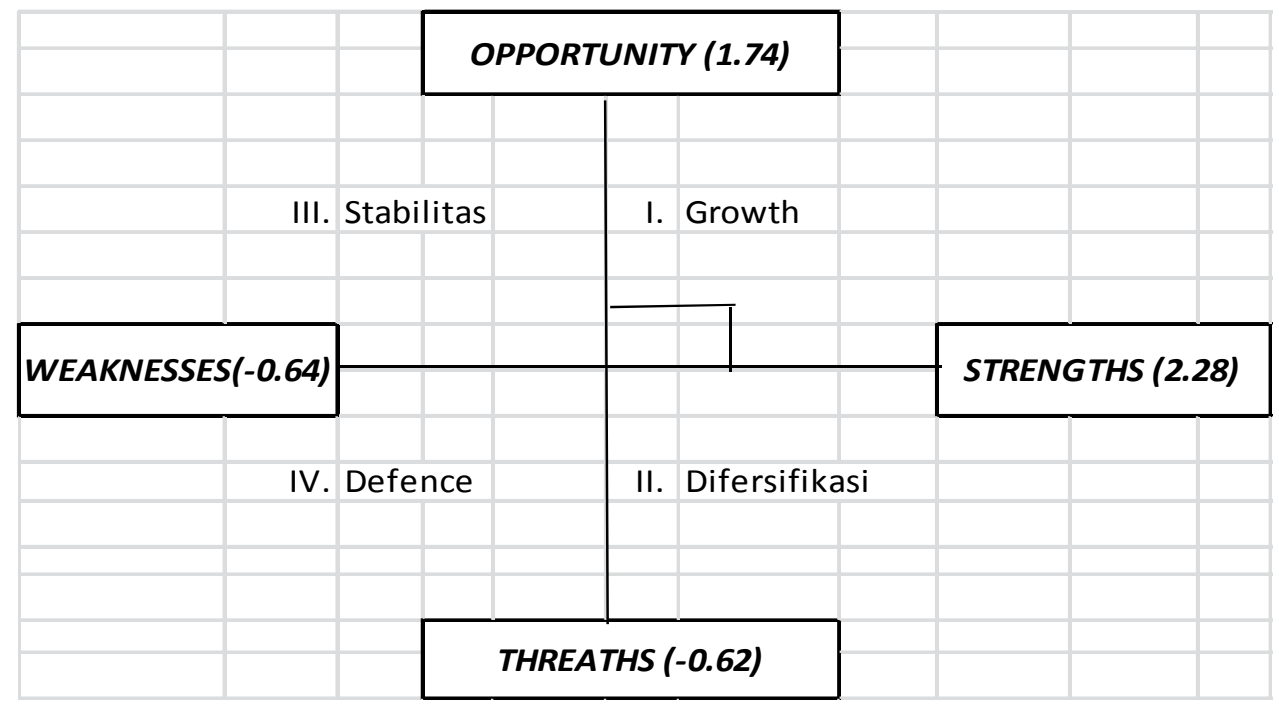

Sumber: Hasil penelitian yang diolah penulis , 2017

Dari nilai total masing-masing faktor selain digambarkan dalam diagram SWOT juga dapat dilakukan analisis model kuantitatif perumusan strategi. 
Pembuatan analisis model kuantitatif tersebut didasarkan pada jumlah nilai skor pada masing-masing faktor yang ada pada masing-masing strategi baik itu pada strategi $S O, W O, S T$ dan $W T$ maka dapat digambarkan model kuantitatif rumusan strategi.

\section{Tabel 3.3}

Tabel, Rumusan Kombinasi Strategi Matrik SWOT

\begin{tabular}{|c|c|c|}
\hline $\mathrm{FFAS}_{\mathrm{EFAS}}^{\text {IFAS }}$ & STRENGTHS (S) & WEAKNESS (W) \\
\hline OPPORTUNITY (O) & $\begin{array}{l}\text { Strategi }(\mathrm{SO}) \text { : } \\
=2.24+1.74 \\
=3.98\end{array}$ & $\begin{array}{l}\text { Strategi (WO): } \\
=0.60+1.74 \\
=2.34\end{array}$ \\
\hline THREAT (T) & $\begin{array}{l}\text { Strategi }(\mathrm{ST}) \text { : } \\
=2.24+0.62 \\
=2.86\end{array}$ & $\begin{array}{l}\text { Strategi (WT): } \\
=0.60+0.62 \\
=1.22\end{array}$ \\
\hline
\end{tabular}

Sumber : Hasil Penelitian yang diolah penulis, 2017

Dari tabel diatas dapat diketahui bahwa matrik perencanaan kombinasi strategi kuantitatif menunjukan bahwa warnet Filistin perlu memanfaatkan strategi $S O$ yang mempunyai nilai skor tertinggi yaitu: 3.98 , selanjutnya diikuti strategi $S T$ : 2.86, strategi $W O: 2.34$ dan strategi $W T: 1.22$.

\section{c. Implementasi Strategi Bisnis}

Mendasari dari hasil analisis diagram SWOT pada gambar 4.1, dimana warnet Filistin berada pada kuadran I yaitu strategi SO (Strengths-Opportunities), maka strategi bisnis yang dapat diimplementasikan yaitu:

\section{Strategi SO (Strengths-Opportunities)}

Strategi SO (Strengths-Opportunities) merupakan strategi yang menggunakan kekuatan internal perusahaan untuk memanfaatkan peluang eksternal yang ada guna 
memperoleh keuntungan bagi perusahaan atau bisnis. Ada alternatif strategi yang dapat dilakukan pada strategi $S O$ yaitu,

a) Menambah usaha baru yang masih ada kaitannya dengan usaha bisnis utama jasa warnet yaitu menambahkan usaha baru misalnya Game Online, menambah fasilitas pengaksesaan internet dengan Hospot Wifi (dengan kartu prabayar/voucher) sehingga bagi para pengguna yang lebih nyaman menggunakan Laptop pribadi dapat mengakses internet di dalam mini kantin.

b) Perluasan pangsa pasar

Melihat pangsa pasar yang masih terbuka selain itu tingkat jumlah penduduk yang meningkat dari tahun ke tahun, maka bisnis usaha jasa warnet ini memperluas usahanya dengan membuka warnet atau cabang baru di daerah lain dengan strategi perencanaan yang matang sehingga tercipta usaha yang berbeda dari yang lain, sehingga semakin banyak masyarakat yang tahu dengan bisnis usaha jasa ini yaitu warnet Filistin.

c) Mempertahankan karyawan yang ada agar dapat mengoptimalkan pelayanan kepada konsumen, dengan memanfaatkan strengths yang ada yakni kemampuan karyawan melayani konsumen dengan baik agar konsumen bisa memilih, melakukan inovasi terus terhadap pelayanan konsumen.

\section{Strategi S-T (Strengths-Threats)}

Implementasi strategi bila suatu usaha berada pada kuadran II yaitu Strategi $S$ $T$ (Strengths-Threats). Strategi ini bertujuan untuk menghindari atau mengurangi dampak dari ancaman-ancaman eksternal dengan menggunakan kekuatan-kekuatan internal yang ada. Karena pada kuadran ini meskipun suatu usaha atau bisnis menghadapi berbagai ancaman, perusahaan masih memiliki kekuatan dari segi internal. Strategi yang harus diterapkan adalah menggunakan peluang jangka panjang dengan cara strategi diversifikasi (Produk/pasar). Alternatif strategi yang dapat dilakukan pada strategi $S-T$ yaitu mempertahankan tingkat harga agar mampu bersaing dengan usaha lain yang sejenis. 


\section{Strategi W-O (Weakness-Opportunities)}

Strategi $W-O$ (Weakness-Opportunities) merupakan strategi di mana suatu perusahaan berada pada kuadran III. Pada kuadran ini perusahaan perusahaan menghadapi peluang pasar yang sangat besar tetapi dilain pihak ia menghadapi beberapa kendala/kelemahan internal. Fokus strateginya adalah dengan meminimalkan masalah-masalah internal perusahaan sehingga dapat merubah peluang pasar yang lebih baik. Implementasi Strategi $W O$ yaitu :

1) Melakukan promosi

2) Memperbaiki atau merenovasi ruangan agar konsumen merasa nyaman berada di dalamnya.

\section{Strategi W-T (Weakness-Threats)}

Strategi $W$-T (Weakness-Threats) merupakan posisi perusahaan berada pada kuadran IV. Dimana situasi yang tidak menguntungkan, karena perusahan menghadapi berbagai ancaman dan kelemahan internal. Untuk itu perusahaan berusaha untuk meminimalkan kelemahan yang dimiliki serta dapat menghindari ancaman dari luar. Ada satu alternative strategi yang dapat dilakukan pada strategi $W$ - $T$ yaitu, meningkatkan kemampuan untuk pengenalan akan keberadaan jasa warnet Filistin. Pengenalan akan dapat dilakukan dengan promosi yang lebih agresif dan intensif, seperti pemasangan papan reklame di tempat-tempat strategis di sekitar wilayah kota Atambua sehingga warnet tersebut dapat diketahui masyarakat umum

\section{Penutup}

\section{Kesimpulan}

Pada hasil analisis data melalui matrik IFAS(Internal Factor Analysis Summary) dan matrik EFAS (Eksternal Factor Analysis Summary) yang diperoleh, Warnet Filistin memiliki bobot yang baik dimana dalam lingkungan internal yang berada dalam posisi Strengths yaitu dengan selisih (1.64) dan lingkungan eksternal yang berada pada posisi Opportunity dengan skor (1.12), sehingga dapat disimpulkan 
bahwa posisi diagram SWOT pada Warnet Filistin berada pada posisi kuadran I (satu) yaitu strategi $S O$ yang menunjukan bisnis usaha ini memiliki peluang dan banyaknya kekuatan yang mendorong dan dimanfaatkannya peluang tersebut.

\section{Saran}

Dari situasi di atas Penulis dapat menyarankan strategi yang berorientasi pada pertumbuhan (Growth Oriented Strategy). Mendasari dari hasil analisis diagram SWOT pada gambar 4.1, dimana warnet Filistin berada pada kuadran I. Posisi ini menandakan sebuah organisasi yang kuat dan berpeluang. Rekomendasi strategi yang diberikan adalah Progresif, artinya organisasi dalam kondisi prima dan mantap sehingga sangat dimungkinkan untuk terus melakukan ekspansi, memperbesar pertumbuhan dan meraih kemajuan secara maksimal maka strategi bisnis yang dapat diimplementasikan yaitu:

a. Menambah usaha baru yang masih ada kaitannya dengan usaha bisnis utama jasa warnet yaitu menambahkan usaha baru yaitu Game Online, menambah fasilitas pengaksesaan internet dengan Hospot Wifi (dengan kartu prabayar/voucher) sehingga bagi para pengguna yang lebih nyaman menggunakan laptop pribadi dapat mengakses internet di dalam mini kantin.

b. Perluasan pangsa pasar

Melihat pangsa pasar yang masih terbuka selain itu tingkat jumlah penduduk yang meningkat dari tahun ke tahun, maka bisnis usaha jasa warnet ini memperluas usahanya dengan membuka warnet atau cabang baru di daerah lain dengan strategi perencanaan yang matang sehingga tercipta usaha yang berbeda dari yang lain, sehingga semakin banyak masyarakat yang tahu dengan bisnis usaha jasa ini yaitu warnet Filistin.

c. Mengoptimalkan pelayanan kepada konsumen, dengan memanfaatkan strengths yang ada yakni kemampuan karyawan melayani konsumen dengan baik agar konsumen bisa memilih, melakukan inovasi terus terhadap pelayanan konsumen. 
Berikut implementasi strategi bila suatu usaha berada pada kuadran II yaitu Strategi S-T (Strengths-Threats). Strategi ini bertujuan untuk menghindari atau mengurangi dampak dari ancaman-ancaman eksternal dengan menggunakan kekuatan-kekuatan internal yang ada. Karena pada kuadran ini meskipun suatu usaha atau bisnis menghadapi berbagai ancaman, perusahaan masih memiliki kekuatan dari segi internal. Strategi yang harus diterapkan adalah menggunakan peluang jangka panjang dengan cara strategi diversifikasi (Produk/pasar). Alternatif strategi yang dapat dilakukan pada strategi $S$ - $T$ yaitu mempertahankan tingkat harga agar mampu bersaing dengan usaha lain yang sejenis.

Strategi W-O (Weakness-Opportunities) merupakan strategi di mana suatu perusahaan berada pada kuadran III. Pada kuadran ini perusahaan perusahaan menghadapi peluang pasar yang sangat besar tetapi dilain pihak ia menghadapi beberapa kendala/kelemahan internal. Fokus strateginya adalah dengan meminimalkan masalah-masalah internal perusahaan sehingga dapat merubah peluang pasar yang lebih baik. Implementasi Strategi $W O$ yaitu

a. Melakukan promosi

b. Memperbaiki atau merenovasi ruangan agar konsumen merasa nyaman berada di dalamnya.

Strategi $W-T$ (Weakness-Threats) merupakan posisi perusahaan berada pada kuadran IV. Dimana situasi yang tidak menguntungkan, karena perusahan menghadapi berbagai ancaman dan kelemahan internal. Untuk itu perusahaan berusaha untuk meminimalkan kelemahan yang dimiliki serta dapat menghindari ancaman dari luar. Ada satu alternative strategi yang dapat dilakukan pada strategi $W-T$ yaitu, meningkatkan kemampuan untuk pengenalan akan keberadaan jasa warnet Filistin. Pengenalan akan dapat dilakukan dengan promosi yang lebih agresif dan intensif, seperti pemasangan papan reklame di tempat-tempat strategis di sekitar wilayah kota Atambua sehingga warnet tersebut dapat diketahui masyarakat umum 
$\mathrm{iE}:$ Inspirasi Ekonomi

Vol. 4 No. 2 Juni 2019 / ISSN: 2503-3123 (Online)

\section{DAFTAR PUSTAKA}

Assauri, S. 1990. Manajemen Pemasaran : Dasar, Konsep dan Strategi. Edisi Pertama. PT. Raja Grafindo Persada. Jakarta

David, F.R. 2002. Manajemen Strategi. Edisi Ketujuh. Terjemahan. PT. Prenhallindo. Jakarta

Frinces, Heflin, Z. 2007. Manajemen Stratrgik (Resep daya saing dan unggul). Mida Pustaka: Jakarta.

Kasmirudin,Army,Chintya.1992.Jurnal Analisis SWOT Sebagai Strategi Meningkatkan Daya Saing Pada Bisnis Usaha Sepatu (Kasus Toko Sepatu Stars Cabang Maproyan Pekanbaru) Pekanbaru ( https://www.google.com), (diakses 12 Januari 2017)

Kofe, Robertus.2012. Skripsi Analisis Strategi Pemasaran (Studi Pada Petani Kacang Tanah di Desa Tuntun) Fakultas Ekonomi, Universitas Timor: Kefamenanu

Kotler, P dan G. Armstrong. 1997. Dasar-dasar Pemasaran. Edisi Bahasa Indonesia. Prenhallindo. Jakarta.

Kotler, Philip. 1998. Manajemen Pemasaran, Analisis, Perencanaan, Implementasi dan kontral. Jilid 2. PT. Prenhallindo, Jakarta

Kotler,Philip. 2000. Manajemen Pemasaran Jilid I Edisi Milenium. Prepalindo: Jakarta

Kotler,Philip. 2002. Manajemen Pemasaran Jilid II. Prepalindo: Jakarta

Kotler,Philip. 2004. Manajemen Pemasaran. Indeks: Jakarta

Kotler, P. 2005. Manajemen Pemasaran. Edisi Kesebelas. Edisi Bahasa Indonesia. PT Indeks (Kelompok Gramedia). Jakarta.

Nafanu,Sirilius. 2015. Modul Kuliah Manajemen Strategi. Universitas Timor: Kefamenanu

Nafanu,Sirilius,Patiung,Marten. 2013. Manajemen Modern edisi I. Absolut Media: Jakarta

Pearce, J.A dan Robinson, R.B. 1997. Manajemen Strategi : Formulasi, Implementasi dan Pengendalian. Edisi Kesatu. Terjemahan. Binarupa Aksara. Jakarta.

Porter, Michael E. 1993. Strategi Bersaing : Teknik Menganalisis Industri dan Pesaing. Alih Bahasa Agus Maulana. Erlangga. Jakarta

Porter, Michael. 1997. Strategi Bersaing Teknik Menganalisis Industri dan Pesaing. Erlangga, Jakarta

Rangkuti, Freddy. 1997. Analisis SWOT Teknik Membedah Kasus Bisnis: Reorientasi Konsep Perencanaan Strategis untuk Menghadapi Abad 21. Gramedia Pustaka Utama:Jakarta

Salusu, J, 2003. Pengambilan Keputusan Stratejik, AT \& Tasindo, Jakarta

Stoner, James A. F., Alih Bahasa Alexander Sindoro, Penyunting Bambang Sayala, 1996, Manajemen. Edisi Keenam, Jilid I, Prehalindo, Jakarta.

Suwarjono, Muhammad. 2000. Manajemen Strategik Konsep dan Kasus, YKPN, Yogyakarta. 